\title{
Controlling the Cassie-to-Wenzel Transition: an Easy Route towards the Realization of Tridimen- sional Arrays of Biological Objects
}

\author{
G. Ciasca ${ }^{1}$ \\ M. Papi ${ }^{1, *}, \quad$ M. Chiarpotto ${ }^{1}$ \\ A. De Ninno ${ }^{2}$, \\ E. Giovine ${ }^{2}$, \\ G. $\mathrm{Campi}^{3}$, \\ A. Gerardino ${ }^{2}, \quad$ M. De \\ Spirito $^{1, *, \dagger}$, \\ L. Businaro ${ }^{2, \dagger}$
}

(Received 14 February 2014; accepted 24 March 2014; published online July 1, 2014)

\begin{abstract}
In this paper we provide evidence that the Cassie-to-Wenzel transition, despite its detrimental effects on the wetting properties of superhydrophobic surfaces, can be exploited as an effective micro-fabrication strategy to obtain highly ordered arrays of biological objects. To this purpose we fabricated a patterned surface wetted in the Cassie state, where we deposited a droplet containing genomic DNA. We observed that, when the droplet wets the surface in the Cassie state, an array of DNA filaments pinned on the top edges between pillars is formed. Conversely, when the Cassie-to-Wenzel transition occurs, DNA can be pinned at different height between pillars. These results open the way to the realization of tridimensional arrays of biological objects.
\end{abstract}

Keywords: Superhydrophobic patterned surfaces; Cassie-to-Wenzel transition; DNA arrays

Citation: G. Ciasca, M. Papi, M. Chiarpotto, A. De Ninno, E. Giovine, G. Campi, A. Gerardino, M. De Spirito and L. Businaro, "Controlling the Cassie-to-Wenzel Transition: an Easy Route towards the Realization of Tridimensional Arrays of Biological Objects", Nano-Micro Lett. 6(3), 280-286 (2014). http://dx.doi.org/ $10.5101 / \mathrm{nml140030 \textrm {a }}$

\section{Introduction}

In the last decades a large effort has been devoted to the realization of microstructured superhydrophobic surfaces, exhibiting both high contact angles (larger than $140^{\circ}-150^{\circ}$ ) and low roll-off angles [1-4]. Thanks to their wetting properties, these surfaces are of increasing interest in a variety of fields including self-cleaning and antifouling surfaces, film coating, MEMS/BioMEMS and microfluidics [5-8].

Two wetting regimes are possible for a water droplet deposited on these surfaces: the Cassie-Baxter state (often referred as suspended state) and the Wenzel state (often referred as impaled state).

In the Cassie-Baxter state, the droplet bridges between surface features with trapped air underneath.
This wetting regime competes with the Wenzel state, where the liquid wets entirely the surface and no air is trapped.

However, a transition between the Cassie-Baxter state and the Wenzel state can easily occur for several reasons, including droplet evaporation [9-12].

For most of the technological application this transition is highly detrimental and needs to be prevented. The Cassie state indeed minimizes the water adhesion, the contact angles hysteresis (the difference between advancing and receding contact angles) and the water rolloff angle [13-15].

These characteristics are key factors in the realization of self-cleaning surfaces. Hence, in many practical applications the Cassie state is preferred over the Wenzel state.

\footnotetext{
${ }^{1}$ Istituto di Fisica, Universitá Cattolica S. Cuore, L.go Francesco Vito 1 I-00168, Roma, Italy

${ }^{2}$ Istituto di Fotonica e Nanotecnologie - CNR, Via Cineto Romano 42, Roma, 00156, Italy

${ }^{3}$ Institute of Crystallography - CNR, Via Salaria Km 29, 0016 Monterotondo Roma, Italy

*Corresponding author. E-mail: m.papi@rm.unicatt.it; m.despirito@rm.unicatt.it

${ }^{\dagger}$ These authors share equal credit for senior authorship.
} 
As a consequence, many studies have been performed to shed light on the mechanism behind this transition with the aim to realize a suspended state as stable as possible [16].

To this purpose, Papadopoulos and co-workers recently imaged the implement dynamics of a drop deposited on a pillar array by confocal microscopy, detailing the Cassie-to-Wenzel transition while it is occurring. Under evaporation condition, they demonstrated the drop rim recedes via stepwise depinning from the edge of the pillars. Once the pressure becomes too high, the drop slowly impales the texture. As soon as the rim touches the substrate, a complete wetting occurs in the millisecond timescale [17].

However, since most of the research effort has been devoted to preserve a stable Cassie state, the possible technological applications of the Cassie-to-Wenzel transition are largely unexplored.

In this paper we provide evidence that this transition - despite its detrimental effect on the surface wetting properties - can provide an effective micro-fabrication strategy to obtain highly ordered tridimensional arrays of biological objects using a bottom-up approach. Toward this end, we fabricated a patterned superhydrophobic surface, where we deposited a droplet containing genomic DNA. We observed that, when the droplet wets the surface in the Cassie state, an array of DNA filaments pinned on the top edges between adjacent pillars is formed. Conversely when the Cassieto-Wenzel transition occurs, DNA bundles can stick at different height between pillars.

\section{Materials and methods}

\section{Fabrication of superhydrophobic surfaces}

Two Different pillar geometries have been tested, namely square-shaped pillars and saw-shaped pillars. The former was fabricated on silicon substrate by electron beam lithography (Vistec EPBG-5HR acceleration voltage: $100 \mathrm{keV}$ ) and Inductive Coupled Plasma (ICP) Si etching. A $1.2 \mu \mathrm{m}$ thick layer of Shipley UVIII electronic resist was spun on the silicon surface, exposed with a dose of $25 \mu \mathrm{C} / \mathrm{cm}^{2}$ and developed. A thin $\mathrm{Cr}$ film $(30 \mathrm{~nm})$ was then deposited and lifted off to define the device pattern: an array of pillars ( $5 \mu \mathrm{m}$ side; $14 \mu \mathrm{m}$ pitch). The device pattern was transferred on the substrate by a two-steps ICP Si etching (First step: protection, pressure: $100 \mathrm{mTorr}, \mathrm{Ar}: 30 \mathrm{sccm}, \mathrm{C}_{4} \mathrm{~F}_{8}: 187$ sccm, ICP: 600 Watt, t: 2s; Second step: etching, pressure: 100mTorr, Ar:100 scccm, SF6: 90 sccm, Cathode bias: 70V, ICP: 500 Watt, t:10s). As for the sawshaped pillars array, a $400 \mathrm{~nm}$ thick layer PMMA 950K $9 \%$ was spun on a $\mathrm{Si}$ wafer, exposed with a dose of $700 \mu \mathrm{C} / \mathrm{cm}^{2}$ and developed. A $30 \mathrm{~nm}$ thick $\mathrm{Cr}$ film was then deposited by e-gun assisted evaporator and lifted off. The device pattern was transferred on the substrate by the same ICP etching procedure. After cleaning in Piranha solution $\left(\mathrm{H}_{2} \mathrm{SO}_{4} / \mathrm{H}_{2} \mathrm{O}_{2}=3: 1\right)$, both microstructured $\mathrm{Si}$ wafers were silanized with $10 \%$ trimethylchlorosilane in toluene to impart the superhydrophobic behavior. This fabrication step is fully discussed in reference [18].

\section{DNA isolation}

DNA isolation was performed according to standard phenol/chloroform protocol. To $1 \mathrm{~mL}$ blood sample (EDTA, heparin, citrate), $0.8 \mathrm{~mL} 1 \mathrm{X}$ SSC buffer was added and mixed. Sample was centrifuged for 1 minute at 12,000 rpm and the supernatant discarded. Then $1 \mathrm{~mL}$ of $1 \mathrm{X}$ SSC buffer was added. The sample was vortexed and centrifuged for 1 minute, and then the supernatant was removed. $375 \mu \mathrm{L}$ of $0.2 \mathrm{M} \mathrm{NaOAc}$ was added to pellet and vortexed briefly. Then $25 \mu \mathrm{L}$ of $10 \%$ SDS and $5 \mu \mathrm{L}$ of proteinase $\mathrm{K}\left(20 \mathrm{mg} / \mathrm{ml}\right.$ in $\left.\mathrm{H}_{2} \mathrm{O}\right)$ (Sigma P-0390) were vortexed briefly and incubated for 4 hour at $55^{\circ} \mathrm{C}$. $120 \mu \mathrm{L}$ phenol/chloroform/isoamyl alcohol were added and vortexed for 30 seconds. The sample was centrifuged for 2 minutes at 12,000 rpm in a microcentrifuge tube. The aqueous layer was removed and transferred to a new $1.5 \mathrm{~mL}$ microcentrifuge tube, and $1 \mathrm{ml}$ of cold $100 \%$ ethanol was mixed and incubated for 15 minutes at $-20^{\circ} \mathrm{C}$. Then the samples were centrifuged for 2 minutes at 12,000 rpm in a microcentrifuge. The supernatant was decanted and drained. $180 \mu \mathrm{L} 10: 1$ of TE buffer were added to the sample, and then the sample was vortexed and incubated at $55^{\circ} \mathrm{C}$ for 10 minutes.

$20 \mu \mathrm{L}$ of sodium acetate $(2 \mathrm{M})$ were added and mixed to the sample. Then $500 \mu \mathrm{L}$ of cold $100 \%$ ethanol was added and centrifuged for 1 minute at 12,000 rpm in a microcentrifuge. The supernatant was decanted and the pellet was rinsed with $1 \mathrm{~mL}$ of $80 \%$ ethanol. After 1 minute centrifugation at $12,000 \mathrm{rpm}$ in a microcentrifuge, the supernatant was decanted and the pellet dried. The pellet was resuspended by adding $200 \mu \mathrm{L}$ of 10:1 TE buffer. After incubation overnight at $55^{\circ} \mathrm{C}$, the sample was vortexed periodically to dissolve the genomic DNA, the DNA concentration was assayed by spectrophotometer $(260 \mathrm{~nm})$ and was $150 \mathrm{ng} / \mathrm{mL}$.

\section{Results and discussion}

Figure 1 shows two SEM micrographs of stretched DNA bundles obtained by the deposition of $5 \mu \mathrm{L}$ genomic DNA solution on a superhydrophobic surface previously wetted in the Cassie state. After the droplet deposition, the patterned surface was tilted by $10^{\circ}$ and the droplet was allowed to completely evaporate before measuring. 

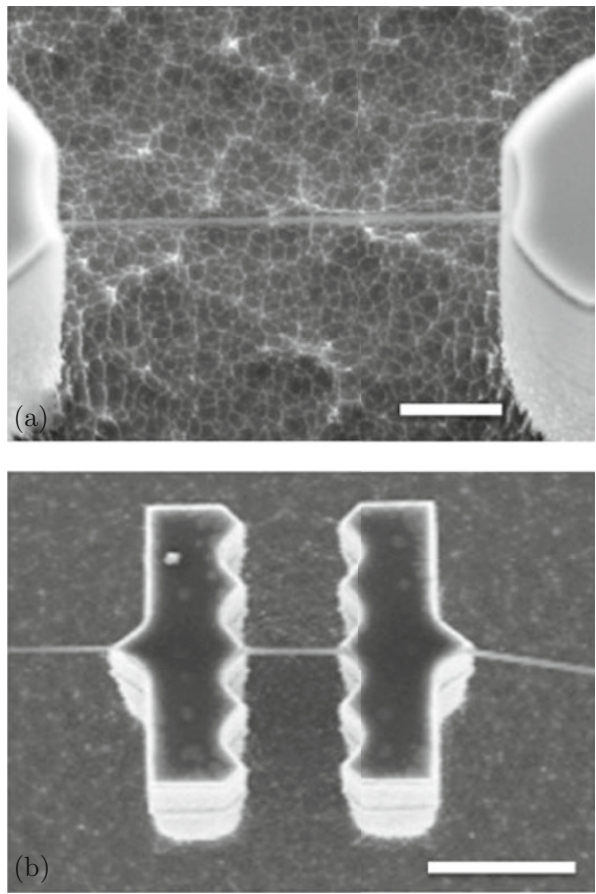

Fig. 1 SEM micrographs show suspended DNA bundles on a square shaped pillar (panel a) and a saw-shaped pillar (Panel b). In both cases DNA bundles are precisely pinned to structural features resembling tips. The scale bar corresponds to a length of $2 \mu \mathrm{m}$ (Panel a) and $5 \mu \mathrm{m}$ (Panel b).

Two superhydrophobic surfaces with different pillar geometries were used: a square shaped geometry containing small protrusions as shown in Fig. 1(a) and a saw-shaped geometry in Fig. 1(b). In both cases, DNA filaments are suspended above pillars and precisely pinned to the pillars' asperities.

Figure 2(a) shows a SEM micrograph of an ordered array of DNA bundles stretched on a superhydrophobic surface with saw-shaped pillars. Two different regions can be clearly distinguished: on the left, three perfectly aligned and suspended DNA bundles can be recognized. The mechanism behind the deposition of aligned and suspended filaments of biological objects is fully detailed in reference [19-22]. Briefly, under evaporation conditions, the retracting drop edge at the three phase contact line stretches the DNA filaments along the de-wetting direction. While receding, the droplet forms capillaries which precisely pin to the pillar protrusions allowing us to control the bundles position and orientation with a high level of accuracy. During this process the drop wets the surface in the Cassie state and therefore the stretched DNA bundles are pinned exclusively on the top of the pillars.

On the right part of the figure, a large DNA deposit can be observed. As demonstrated in reference 9 and 24 , the presence of this deposit indicates the occurrence of a Cassie-to-Wenzel transition. The solute indeed remained not only at the top of the pillars but also at the bottom,proving that the drop sank inside the texture.

Figure 2(b) shows a SEM micrograph of the whole DNA deposit. The deposit has a circular shape with a radius of few hundreds of microns.

In Fig. 2(c) an enlarged details of the outer rim of the deposit are shown. Two stretched DNA bundles suspended above the solute deposit are highlighted by red arrows.

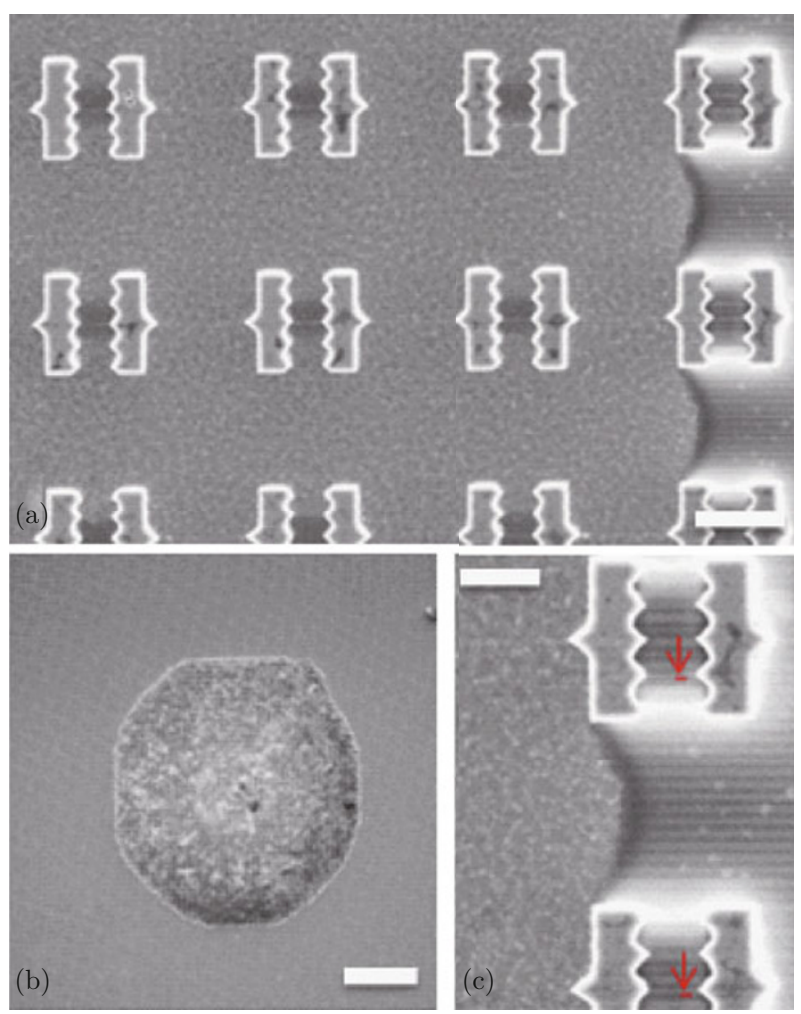

Fig. 2 (Panel a)SEM micrograph of an ordered array of DNA bundles stretched on a saw-shaped superhydrophobic surface. Three perfectly aligned and suspended DNA bundles can be recognized on the left part of the surface, whereas a large DNA deposit can be recognized on the right part of the image. (Panel b) SEM micrograph of the whole DNA deposit. (Panel c) Enlarged detail of the outer rim of the deposit. Two stretched DNA bundles suspended above the deposit are highlighted by red arrows. The scale bar corresponds to a length of $10 \mu \mathrm{m}$ (panel a), $200 \mu \mathrm{m}$ (Panel b) and $5 \mu \mathrm{m}$ (Panel $\mathrm{c})$.

The presence of these filaments can be explained by taking into account the peculiar Cassie-to-Wenzel transition dynamics.

As the drop volume reduces, the drop contact line slides inward, with a consequent decrease in the rim diameter.During its motion, the contact line stretches DNA bundles above pillars (this step is schematically represented in Fig. 3(a) and Fig. 3(b)). However, as soon as the Cassie-to-Wenzel transition occurs, it is accompanied by a decrease of the apparent contact angle by a few degrees. Therefore, in order to conserve the drop volume, the contact line jumps back 
outward with a consequent increase in the rim diameter (Fig. 3(c)). Then the contact line remains pinned during further evaporation causing the solute deposition also in the region where, immediately before the transition, DNA filaments have been stretched above pillars (Fig. 3(d)). The above described wetting dynamics fully explains the coexistence in the same sample region of suspended DNA filaments and the DNA deposit observed in Fig. 2(c).

Before the Cassie-to-Wenzel transition

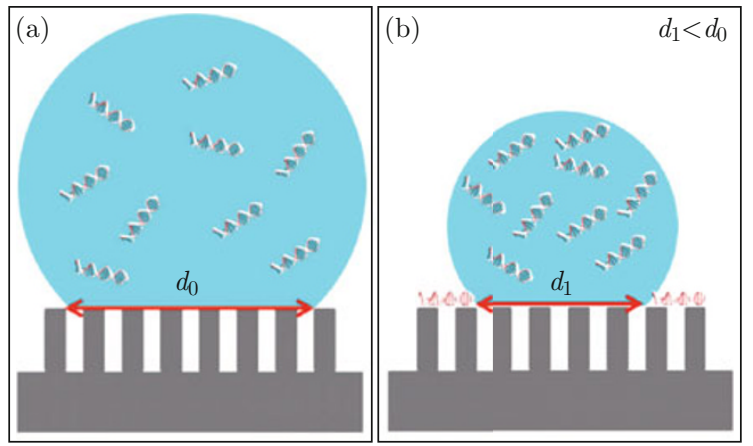

After the Cassie-to-Wenzel transition

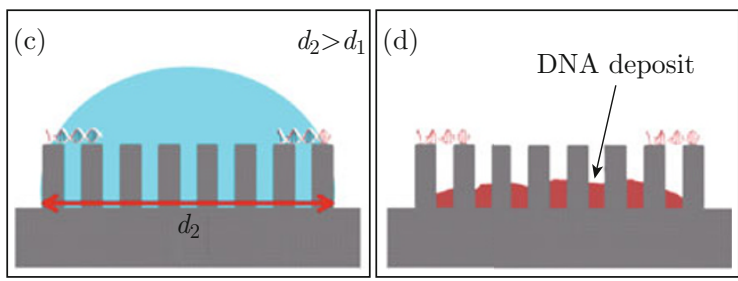

Fig. 3 (Panel a) Schematic view of the Cassie-to-Wenzel transition leading to the DNA deposit formation. Under evaporation conditions, when the drop is in the Cassie state, the drop contact line slides inward, with a consequent decrease in the rim diameter $\left(d_{0}>d_{1}\right)$. The rim motion stretches DNA bundles above pillars (panel a and b). After the transition the drop rim jumps back outward with a consequent increase in the rim diameter $\left(d_{2}>d_{1}\right)$ (Panel c). The contact line remains pinned during further evaporation causing the solute deposition (Panel c and d).

In Fig. 4 two large ordered arrays of stretched DNA bundles are shown. These arrays are obtained before (panel a) and after (panel b) the occurrence of the Cassie-to-Wenzel transition. In the latter case the SEM micrograph has been acquired inside the DNA deposit. It is worth stressing here that DNA deposits are generally not homogenous. Therefore both ordered regions (as shown in Fig. 4(b)) and disordered regions (as in Fig. 2(a) and 2(c)) can be found. This phenomenon is still not fully understood and therefore it needs further in-depth studies. However, in this case, we can estimate a yield for the ordered state of about 15\%. Before the transition, DNA bundles are suspended above pillars and precisely pinned to the pillar protrusions. The suspended DNA bundles are monodisperse in sizes, showing a diameter distribution ranging between $20 \mathrm{~nm}$ and
$30 \mathrm{~nm}[19]$.

After the transition, DNA bundles are not suspendedabove pillars anymore (Fig. 2(c)) in Fig. 4(b). Conversely, they stick to the lower part of the pillars. An enlarged detail of the sticking point is shown in Fig. 5(a), where two DNA bundles are stuck at about 6 microns and 9 microns from the pillar base. As can be clearly observed in Fig. 5(b), after the transition, bundles are larger than those in Fig. 4(a), showing a diameter of few hundreds of nanometres. This is probably due to the fact that DNA concentration in solution increases as the drop volume reduces.
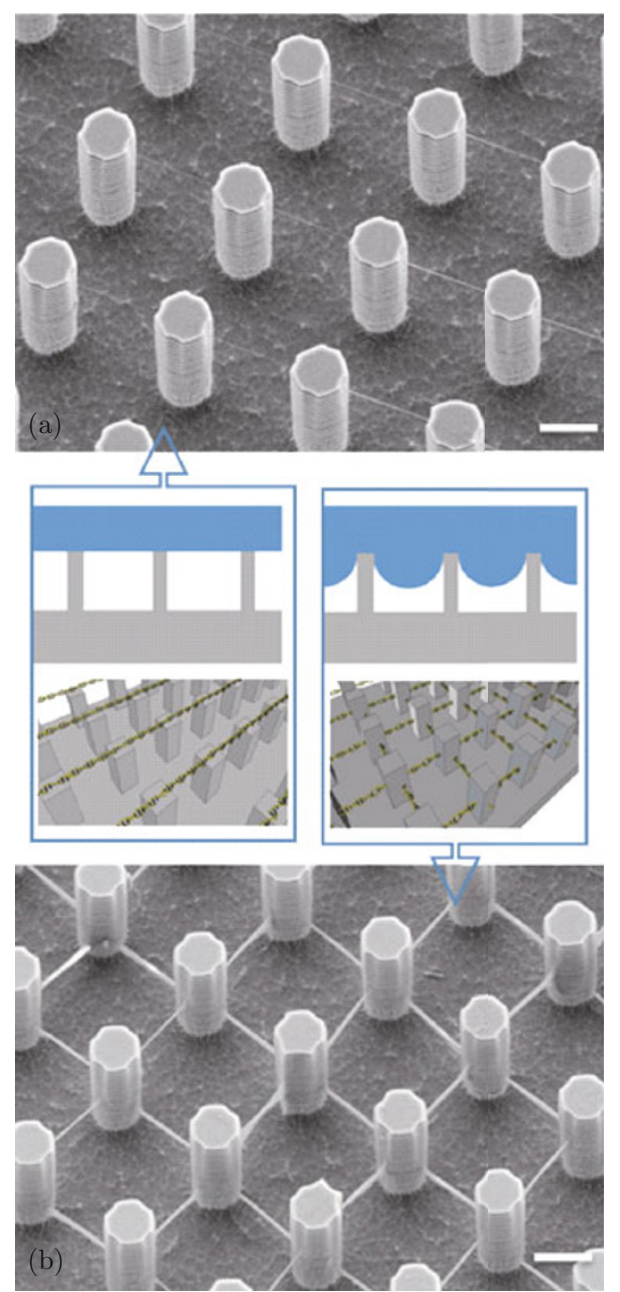

Fig. 4 SEM micrograph of two large ordered arrays of stretched DNA bundles. These arrays are obtained before (Panel a) and after (Panel b) the occurrence of the Cassieto-Wenzel transition. The scale bar corresponds to a length of $5 \mu \mathrm{m}$. The ordered array shown in panel $\mathrm{b}$ has been acquired in the square-shaped region highlighted in Fig. 2(b).

It can be noted that DNA bundles in Fig. 4(b) and Fig. 5(a) are not deposited at the pillar base. This fact indicates that the portion of the drop responsible of the bundles formation was in a metastable Cassie state [24]. In this state Laplace pressure is insufficient to 
overcome the energy barrier required to completely wet the surface, but it is high enough to wet a portion of the pillars wall. This consideration suggests that DNA bundles can be deposited at different height by controlling Laplace pressure as schematically represented in Fig. 5.
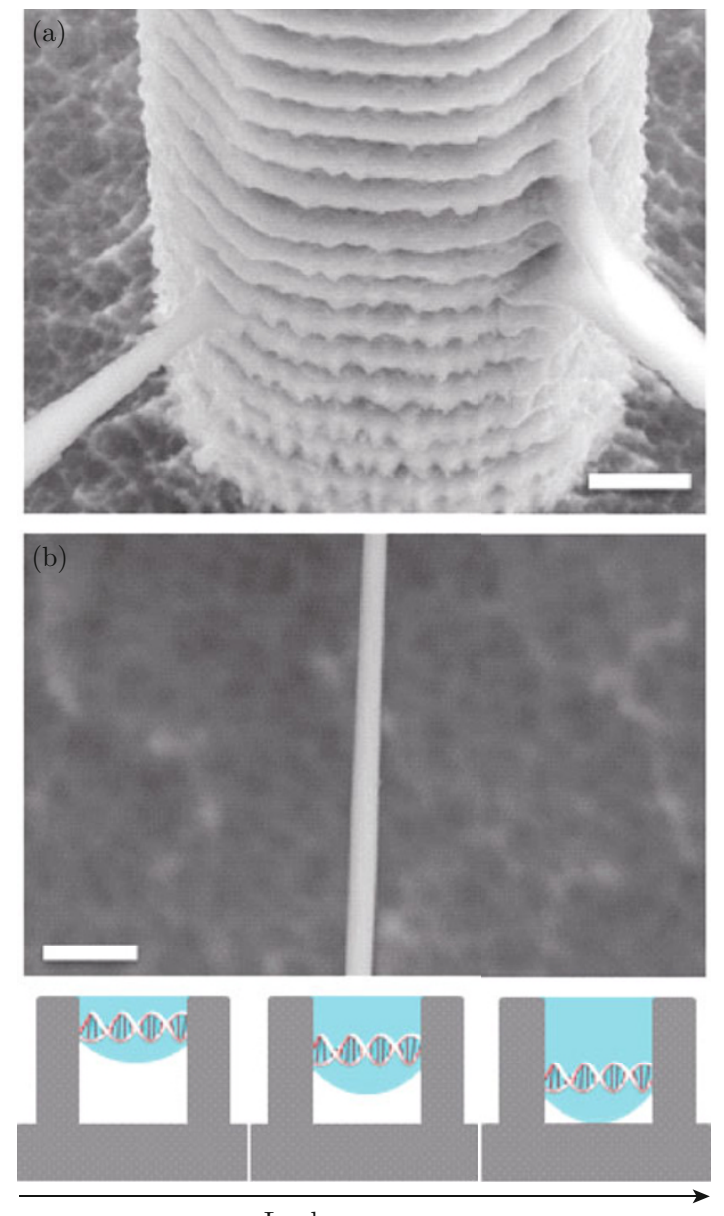

Laplace pressure

Fig. 5 (Panel a) SEM micrograph of the sticking point of two DNA bundles. (Panel b) SEM micrograph of a single DNA bundle obtained after the occurrence of the Cassie-toWenzel transition. Bundle diameter is $230 \mathrm{~nm}$. (Bottom) Schematic view of the role of the Laplace pressure in the formation of the DNA bundles. The scale bar corresponds to a length of $1 \mu \mathrm{m}$.

In particular several models have been proposed to calculate the drop penetration depth between pillars. Jung and Bhushan proposed a very simple model for an ordered array of circular pillars. According to their model, the maximum droop $\delta$ of the droplet can be calculated by the formula $\delta=(\sqrt{2} P-D)^{2} /(8 R)$, where $R$ is the radius of the drop, $D$ is the pillar diameter and $P$ is the array pitch [25].

This equation suggests that several parameters can be varied to control the drop penetration depth and therefore the DNA sticking point. In particular,
Laplace pressure can be tuned by varying the initial drop volume according to its radius $R$. Moreover, further design parameters that can be varied are the pillar sizes (such as the pillar diameter) and the array pitch $P$. The control of these parameters can be easily achieved thanks to the standard lithographic techniques, and can provide a fine tuning of the sticking point of the DNA bundles.

Our findings suggest that a tridimensional ordered array of DNA molecules can be obtained by the deposition of several droplet on the same substrateby varying the droplet initial position and volume, and the latter controlling the Laplace pressure.

The precise control of the DNA position demonstrated here can be exploited for the development of novel micro-devices with potential application in a wide range of genetic studies. The fabrication of large ordered DNA arrays has been proposed as a promising strategy to perform highly automated analysis in the next-generation DNA chips [26]. Moreover thanks to its high aspect ratio, DNA is also an attractive candidate for the realization of highly aligned 1D nanostructure, showing the potential to address many challenges in electronics [27-29]. To this purpose, the precise controlling over the DNA positioning in the three directions of the space could help the integration of functional DNA filament into devices, since the integration process usually starts from the fabrication of metallic electrodes followed by the alignment of DNA above the electrodes.

Beside DNA applications, the ability to precisely position biological objects in a defined portion of space, could have a positive impact on the study of blood proteins, such as ferritin and low density lipoproteins, which are often available in very limited quantity [3035]. Furthermore, this system could be particularly important as a scaffold for the growth of controlled networks of biological molecules [36-38].

\section{Conclusions}

In this paper we demonstrate the possibility to realize highly ordered arrays of stretched DNA bundles by using superhydrophobic patterned surfaces initially wetted in the Cassie-Baxter state. To this purpose we fabricated two superhydrophobic pillar surfaces with different pillar geometries. In both cases, the pillars were decorated with small features resembling tips. These structures allowed us to obtain a fine control over the DNA bundles position in the plane parallel to the device surface.

Moreover we investigated the possibility to exploit the Cassie-to-Wenzel transition in order to control also the DNA sticking point in the third direction of the space. In particular we found that, when the superhy- 
drophobic surfaces are wet in the Cassie state, the DNA bundles stick exclusively above pillars. However, under evaporation conditions, a transition between the Cassie state and a Wenzel state occurs as a consequence of an increase in the Laplace pressure which, in its turn, is due to a decrease in the drop radius. After the transition, a large ordered array of DNA bundles can be found. However, DNA bundles do not stick on the pillar top surface; they stick on the lower part of the pillars instead.

These results open the way to realization of tridimensional self-assembled arrays of DNA bundles showing the potential to address challenges in several field including DNA electronics and the development of novel DNA chips for genetic analysis.

\section{References}

[1] W. Barthlott and C. Neinhuis, "Purity of the sacred lotus, or escape from contamination in biological surfaces", Planta Med. 202(1), 1-8 (1997). http://dx. doi.org/10.1007/s004250050096

[2] T. Wagner, C. Neinhuis and W. Barthlott, "Wettability and contaminability of insect wings as a function of their surface sculptures", Acta Zoologica. 77(3), 213-225 (1996). http://dx.doi.org/10.1111/ j.1463-6395.1996.tb01265.x

[3] X. M. Li, D. Reinhoudt andM. Crego-Calama, "What do we need for a superhydrophobic surface? A review on the recent progress in the preparation of superhydrophobic surfaces", Chem. Soc. Rev. 36(8), 1350-1368 (2007). http://dx.doi.org/10.1039/B602486F

[4] X. Deng, L. Mammen, Y. Zhao, P. Lellig, K. Müllen, C. Li andD. Vollmer, "Transparent, thermally stable and mechanically robust superhydrophobic surfaces made from porous silica capsules", Adv. Mater. 23(26), 2962-2965 (2011). http://dx.doi.org/10. 1002/adma. 201100410

[5] C. I. Park, H. E. Jeong, S. H. Lee, H. S. Cho and K. Y. Suh, "Wetting transition and optimal design for microstructured surfaces with hydrophobic and hydrophilic materials", J. Colloid Interface Sci. 336(1), 298-303 (2009). http://dx.doi.org/10.1016/ j.jcis.2009.04.022

[6] E Greco, M. B. Santucci, M. Sali, F. R. De Angelis, M. Papi, M. De Spirito, G. Delogu, V. Colizzi and M. Fraziano, "Natural lysophospholipids reduce mycobacterium tuberculosis-induced cytotoxicity and induce anti-mycobacterial activity by a phagolysosome maturation-dependent mechanism in A549 type II alveolar epithelial cells", Immunology 129(1), 125-132 (2010). http://dx.doi.org/10.1111/ j.1365-2567.2009.03145.x

[7] Z. Burton and B. Bhushan, "Hydrophobicity, adhesion, and friction properties of nanopatterned polymers and scale dependence for micro-and nanoelectromechanical systems", Nano Lett. 5(8), 1607-1613 (2005). http://dx.doi.org/10.1021/n1050861b
[8] H. Ren, R. B. Fair, M. G. Pollack and E. J. Shaughnessy, "Dynamics of electro-wetting droplet transport", Sens.Actuators B: Chemical 87(1), 201-206 (2002). http://dx.doi.org/10.1016/ S0925-4005(02) 00223-X

[9] M. Reyssat, J. M. Yeomans and D. Quéré, "Impalement of fakir drops", Europhys. Lett. 81(2), 26006 (2008). http://dx.doi.org/10.1209/0295-5075/81/ 26006

[10] H. Kusumaatmaja, M. L. Blow, A. Dupuis and J. M. Yeomans, "The collapse transition on superhydrophobic surfaces", Europhy. Lett. 81(3), 36003 (2008). http://dx.doi.org/10.1209/0295-5075/81/36003

[11] G. McHale, S. Aqil, N. J. Shirtcliffe, M. I. Newton and H. Y. Erbil, "Analysis of droplet evaporation on a superhydrophobic surface", Langmuir21(24), 11053-11060 (2005). http://dx.doi.org/ 10.1021/la0518795

[12] D. H. Kwon and S. J. Lee, "Impact and wetting behaviors of impinging microdroplets on superhydrophobic textured surfaces", Appl. Phys. Lett. 100(17), 171601 (2012). http://dx.doi.org/10.1063/1.4705296

[13] C. W. Extrand, "Model for contact angles and hysteresis on rough and ultraphobic surfaces", Langmuir 18(21), 7991-7999 (2002). http://dx.doi.org/ 10.1021/la025769z

[14] J. Kijlstra, K. Reihs and A. Klamt, "Roughness and topology of ultra-hydrophobic surfaces", Colloids Surf. A 206(1-3), 521-529 (2002). http://dx.doi.org/10. 1016/S0927-7757 (02)00089-4

[15] Y. C. Jung and B. Bhushan, "Contact angle, adhesion and friction properties of micro-and nanopatterned polymers for superhydrophobicity", Nanotechnology 17(19), 4970 (2006). http://dx.doi.org/10. 1088/0957-4484/17/19/033

[16] A. Cavalli, P. Bøggild and F. Okkels, "Topology optimization of robust superhydrophobic surfaces", Soft Matter 9(7), 2234-2238 (2013). http://dx.doi.org/ 10.1039/C2SM27214H

[17] P. Papadopoulos, L. Mammen, X. Deng, D, Vollmer and H. J. Butt, "How superhydrophobicity breaks down", Proc. Natl. Acad. Sci. 110(9), 32543258 (2013). http://dx.doi.org/10.1073/pnas. 1218673110

[18] G. Ciasca, L. Businaro, A. De Ninno, A. Cedola, A. Notargiacomo, G. Campi and A. Gerardino, "Wet sample confinement by superhydrophobic patterned surfaces for combined X-ray fluorescence and X-ray phase contrast imaging", Microelectron. Eng. 111, 304-309 (2013). http://dx.doi.org/10.1016/j.mee. 2013.02.020

[19] G. Ciasca, L. Businaro, M. Papi, A. Notargiacomo, M. Chiarpotto, A. De Ninno and M. De Spirito, "Self-assembling of large ordered DNA arrays using superhydrophobic patterned surfaces", Nanotechnology24(49), 495302 (2013). http://dx.doi.org/10. 1088/0957-4484/24/49/495302

[20] F. Gentile, M. Moretti, T. Limongi, A. Falqui, G. Bertoni, A. Scarpellini and E. di Fabrizio, "Direct 
imaging of dnafibers: the visage of double helix", Nano Lett. 12(12), 6453-6458 (2012). http://dx.doi.org/ 10.1021/nl3039162

[21] F. De Angelis, F. Gentile, F. Mecarini, G. Das, M. Moretti, P. Candeloro and E. Di Fabrizio, "Breaking the diffusion limit with super-hydrophobic delivery of molecules to plasmonicnanofocusing SERS structures", Nature Photonics 5(11), 682-687 (2011). http://dx.doi.org/10.1038/nphoton.2011. 222

[22] B. Su, S. Wang, J. Ma, Y. Wu, X. Chen, Y. Song and L. Jiang, "Elaborate positioning of nanowire arrays contributed by highly adhesive superhydrophobic pillar-structured substrates" Adv. Mater. 24(4), 559-564 (2012). http://dx.doi.org/10.1002/adma. 201104019

[23] Y. C. Jung and B. Bhushan, "Wetting transition of water droplets on superhydrophobic patterned surfaces", Scripta Materialia 57, 1057-1060 (2007). http://dx. doi.org/10.1016/j.scriptamat.2007.09.004

[24] K. K. Varanasi, T. Deng, M. F. Hsu and N. Bhate, "Design of superhydrophobic surfaces for optimum roll-off and droplet impact resistance", American Society of Mechanical EngineersIMECE200867808, 637-645 (2008). http://dx.doi.org/10.1115/ IMECE2008-67808

[25] B. Bhushan and Y. C. Jung, "Natural and biomimetic artificial surfaces for superhydrophobicity, self-cleaning, low adhesion, and drag reduction", Progress in Materials Science 56(1), 1108 (2011). http://dx.doi.org/10.1016/j.pmatsci. 2010.04 .003

[26] J. Guan and L. J. Lee, "Generating highly ordered DNA nanostrand arrays", Proc. Natl. Acad. Sci. U.S.A. 102(51), 18321-18325 (2005). http://dx.doi. org/10.1073/pnas. 0506902102

[27] A. D. Chepelianskii, D. Klinov, A. Kasumov, S. Guéron, O. Pietrement, S. Lyonnais and H. Bouchiat, "Long range electronic transport in DNA molecules deposited across a disconnected array of metallic nanoparticles", ComptesRendus Physique 13(910), 967-992 (2012). http://dx.doi.org/10.1016/j . crhy. 2012.10.007

[28] D. S. Hopkins, D. Pekker, P. M. Goldbart and A. Bezryadin, "Quantum interference device made by DNA templating of superconducting nanowires", Science 308(5729), 1762-1765 (2005). http://dx.doi. org/10.1126/science. 1111307

[29] F. Patolsky, G. Zheng and C. M. Lieber, "Nanowirebased biosensors", Anal. Chem. 78(13), 4260-4269 (2006). http://dx.doi.org/10.1021/ac069419j

[30] M. De Spirito, R. Brunelli, G. Mei, F. R. Bertani, G. Ciasca, G. Greco, M. Papi, G. Arcovito, F. Ursini and T. Parasassi "Low density lipoprotein aged in plasma forms clusters resembling subendothelial droplets: aggregation via surface sites", Biophys.J. 90(11), 42394247 (2006). http://dx.doi.org/10.1529/biophysj . 105.075788

[31] M. Chiarpotto, G. Ciasca, M. Vassalli, C. Rossi, G. Campi, A. Ricci, B. Bocca, A. Pino, A. Alimonti, P. De Sole and M. Papi, "Mechanism of aluminium biomineralization in the apoferritin cavity", Appl. Phys. Lett.103(8), 083701 (2013). http://dx.doi.org/10. 1063/1. 4818749

[32] P. De Sole, C. Rossi, M. Chiarpotto, G. Ciasca, B. Bocca, A. Alimonti, A. Bizzarro, C. Rossi and C. Masullo "Possible relationship between $\mathrm{Al} /$ ferritin complex and Alzheimer's disease", Clin. Biochem. 46(1-2), 89-93 (2013). http://dx.doi.org/10.1016/ j.clinbiochem. 2012.10.023

[33] G. Ciasca, M. Papi, M. Chiarpotto, M. Rodio, G. Campi, C. Rossi, P. De Sole and A. Bianconi, "Transient state kinetic investigation of ferritin iron release", Appl. Phys. Lett. 100(7), 073703 (2012). http://dx. doi.org/10.1063/1.3685706

[34] G. Ciasca, M. Chiarpotto, G. Campi, B. Bocca, M. Rodio, A. Pino, A. Ricci, N. Poccia, C. Rossi, A. Alimonti, H. Amenitsch, P. De Sole and A. Bianconi, "Reconstitution of aluminium and iron core in horse spleen apoferritin", J. Nanopart. Res. 13(11), 6149-6155 (2011). http://dx.doi.org/10. 1007/s11051-011-0294-2

[35] M. Papi, G. Maulucci, M. De Spirito, M. Missori, G. Arcovito, S. Lancellotti, E. Di Stasio, R. De Cristofaro and A. Arcovito, "Ristocetin-induced selfaggregation of von Willebrand factor", Eur. Biophysics J. 39(12), 1597-1603, 2010. http://dx.doi.org/10. 1007/s00249-010-0617-8

[36] G. Campi, A. Ricci, A. Guagliardi, C. Giannini, S. Lagomarsino, R. Cancedda, M. Mastrogiacomo and A. Cedola, "Early stage mineralization in tissue engineering mapped by high resolution X-ray microdiffraction", ActaBiomaterialia 8(9), 3411-3418(2012). http://dx.doi.org/10.1016/j . actbio.2012.05.034

[37] G. Campi, G. Pezzotti, M. Fratini, A. Ricci, M. Burghammer, R. Cancedda, M. Mastrogiacomo, I. Bukreeva and A. Cedola, "Imaging regenerating bone tissue based on neural networks applied to micro-diffraction measurements", Appl. Phys. Lett. 103(25), 253703(2013). http://dx.doi.org/10.1063/ 1.4852056

[38] M. De Spirito, M. Missori, M. Papi, G. Maulucci, J. Teixeira, C, Castellano and G. Arcovito, "Modifications in solvent clusters embedded along the fibers of a cellulose polymer network cause paper degradation", Phys. Rev. E 77(4), 041801 (2008). http://dx.doi. org/10.1103/PhysRevE.77.041801 